\title{
Beef meat promotion of dimethylhydrazine-induced colorectal carcinogenesis biomarkers is suppressed by dietary calcium
}

\author{
Fabrice Pierre ${ }^{1 *}$, Raphaëlle Santarelli ${ }^{1}$, Sylviane Taché ${ }^{1}$, Françoise Guéraud ${ }^{2}$ and Denis E. Corpet ${ }^{1}$ \\ ${ }^{1}$ UMR1089 Xénobiotiques, INRA-ENVT, 23 ch. Capelles, F-31076 Toulouse, France \\ ${ }^{2}$ Institut National de la Recherche Agronomique, 180 ch. Tournefeuille, F-31931 Toulouse, France
}

(Received 22 June 2007 - Revised 28 August 2007 - Accepted 6 September 2007 - First published online 22 October 2007)

Red meat consumption is associated with increased risk of colorectal cancer. We have previously shown that haemin, Hb and red meat promote carcinogen-induced preneoplastic lesions: aberrant crypt foci (ACF) and mucin-depleted foci (MDF) in rats. We have also shown that dietary $\mathrm{Ca}$, antioxidant mix and olive oil inhibit haemin-induced ACF promotion, and normalize faecal lipoperoxides and cytotoxicity. Here we tested if these strategies are effective also against red meat promotion in dimethylhydrazine-induced rats. Three diets with $60 \%$ beef meat were supplemented with calcium phosphate $(31 \mathrm{~g} / \mathrm{kg}$ ), antioxidant agents (rutin and butylated hydroxyanisole, $0.05 \%$ each) and olive oil (5\%). ACF, MDF, faecal water cytotoxicity, thiobarbituric acid reactive substances (TBARS) and urinary 1,4-dihydroxynonane mercapturic acid (DHNMA) were measured. Beef meat diet increased the number of ACF $(+30 \%)$ and MDF $(+100 \%)(P<0 \cdot 001)$, which confirms our previous findings. Promotion was associated with increased faecal water TBARs $(\times 4)$ and cytotoxicity $(\times 2)$, and urinary DHN-MA excretion $(\times 15)$. Ca fully inhibited beef meat-induced ACF and MDF promotion, and normalized faecal TBARS and cytotoxicity, but did not reduce urinary DHNMA. Unexpectedly, high-calcium control diet-fed rats had more MDF and ACF in the colon than low-Ca control diet-fed rats. Antioxidant mix and olive oil did not normalize beef meat promotion nor biochemical factors. The results confirm that haem causes promotion of colon carcinogenesis by red meat. They suggest that $\mathrm{Ca}$ can reduce colorectal cancer risk in meat-eaters. The results support the concept that toxicity associated with the excess of a useful nutrient may be prevented by another nutrient.

Red meat: Colorectal cancer: Aberrant crypt foci: Carcinogenesis promotion

Red and processed meat consumption increases the risk of colorectal cancer, according to meta-analyses of epidemiological studies ${ }^{(1,2)}$. Several explanations have been given for this increase, involving fat, heterocyclic amines, $\mathrm{N}$-nitrosated compounds and haem iron. Intake of dietary haem iron is associated with an increased risk of colon cancer among women of the Iowa Women's Health Study ${ }^{(3)}$. Intake of black pudding, a blood sausage high in haem iron, is associated with increased risk of colorectal cancer among women of the Swedish Mammography Cohort ${ }^{(4)}$.

Experimental animal studies support the hypothesis that haem $\mathrm{Fe}$ promotes colorectal carcinogenesis ${ }^{(5)}$. We have shown that dietary haem, in the form of haemin, $\mathrm{Hb}$ or red meat, promotes putative precancerous lesions, aberrant crypt foci (ACF) and mucin-depleted foci (MDF) in the colon of rats given a low-Ca $\operatorname{diet}^{(6,7)}$. Haemin is a free haem ring stabilized by a chlorine atom, in contrast with chlorine-free protein-bound haem in meat myoglobin. This haem-induced promotion is associated with increased lipoperoxidation and cytotoxicity of faecal water, and linked to urinary 1,4dihydroxynonane mercapturic acid (DHN-MA) excretion, a lipid peroxidation biomarker ${ }^{(8)}$. The addition of $\mathrm{Ca}$, antioxidant mix or olive oil to the diet inhibits haemin-induced lipoperoxidation, cytotoxicity and promotion of carcinogenesis in rats ${ }^{(6)}$, but no demonstration has already been given that these dietary factors can inhibit promotion by red meat. We thus suggested, after Sesink et al. ${ }^{(9)}$, that diets high in $\mathrm{Ca}$ and oxidation-resistant fat could prevent promotion by red meat.

The present study was designed to test the hypothesis that the addition of $\mathrm{Ca}$, antioxidant mix or olive oil to the diet can inhibit the cancer-promoting effect of haem provided by beef meat.

\section{Materials and methods \\ Animals and diets}

Eighty Fischer 344 female rats were purchased at 4 weeks of age from Iffa Credo (St. Germain l'Arbresle, France). Animal care was in accordance with the guidelines of the European Council on animals used in experimental studies. The animal colony and staff got an official agreement \#31-121 for in vivo rodent studies by the French government. Rats were housed by pairs in stainless steel wire-bottomed cages. The room was kept at a steady acclimatization to the animal

Abbreviations: ACF, aberrant crypt foci; DHN-MA, 1,4-dihydroxynonane mercapturic acid; HNE, 4-hydroxynonenal; MDF, mucin-depleted foci; TBARS, thiobarbituric acid reactive substances.

* Corresponding author: Dr Fabrice Pierre, fax +33 561491 263, email f.pierre@envt.fr 
colony and the rats were given control diet before being injected intraperitoneally with the carcinogen 1,2-dimethylhydrazine (Sigma Chemical, St. Quentin, France; $190 \mathrm{mg} / \mathrm{kg}$ body weight) in $\mathrm{NaCl}(9 \mathrm{~g} / \mathrm{l})$. Usually, several injections are given to rats. We reasoned that the first shot initiates carcinogenesis, and the following shots promote it, blurring dietinduced promotion. We thus chose a single-shot protocol, following Karkare et al. ${ }^{(10)}$. Rats were randomly allocated to eight groups of ten $7 \mathrm{~d}$ later, and allowed free access to their respective diet for $100 \mathrm{~d}$. We chose to initiate all rats with the carcinogen, since the study was designed to show dietary promotion, and because a $2.5 \% \mathrm{Hb}$ diet does not initiate $\mathrm{ACF}$ in rats (F Pierre and DE Corpet, unpublished results).

Eight experimental diets shown in Table 1 were based on the diet fed to control rats, a modified AIN-76 powdered $\operatorname{diet}^{(11)}$ prepared and formulated in a powdered form by UPAE (INRA, Jouy-en-Josas, France). Dibasic calcium phosphate was included at a low concentration of $2.7 \mathrm{~g} / \mathrm{kg}$. Four beef meat diets were formulated to contain $60 \%$ meat (w/w, freeze-dried). Beef meat contained $0.6 \mu \mathrm{mol} / \mathrm{g}$ haem. We chose this meat level, higher than what most people eat, to be able to detect protection against promotion. The effect of $\mathrm{Ca}$ and of an antioxidant mix was tested in two groups of rats given a beef meat diet supplemented either with calcium phosphate $(31 \mathrm{~g} / \mathrm{kg})$ or antioxidant mix (butylated hydroxyanisole and rutin, $0.05 \%$ each). Last, the effect of oil was investigated by replacing safflower oil by extra-virgin olive oil ( $5 \%$; Puget, France) in a beef meat diet. Because Ca, antioxidant mix and olive oil might be protective even in the absence of meat, three other groups received beef-free control diet, supplemented with calcium phosphate, antioxidant mix or olive oil. As shown in Table 1, all diets were balanced for protein $(50 \%)$, fat $(20 \%)$ and $\mathrm{Fe}(110 \mathrm{mg} / \mathrm{kg})$ by addition of casein, lard and ferric citrate. The diets were made up every $14 \mathrm{~d}$ and maintained at $-20^{\circ} \mathrm{C}$ to reduce lipoperoxidation.

\section{Aberrant crypt foci assay}

All eighty rats were killed by $\mathrm{CO}_{2}$ asphyxiation in a random order at day 99 or 100 . Colons were excised from rats immediately post mortem, flushed with cold Krebs solution (Sigma Chemical), opened longitudinally and fixed flat between two sheets of filter paper in $10 \%$ formalin (Sigma Chemical). Eighty colons picked up in random order were stained for $6 \mathrm{~min}$ in a $0.05 \%$ filtered solution of methylene blue ${ }^{(12)}$. The number of ACF per colon, and number of crypts in each $\mathrm{ACF}$, were counted under light microscope at $\times 40$ magnification in duplicate by two readers, blinded for the origin of the colon. Data from the two readers were pooled.

\section{Mucin-depleted foci assay}

MDF may predict colon carcinogenesis better than ACF, since Apc mutations are present in MDF with a frequency similar to that of tumours ${ }^{(13)}$. Colons, after being scored for ACF, were stained with a high $\mathrm{Fe}$ diamine-Alcian blue procedure to evaluate mucin production ${ }^{(14)}$. Briefly, colons were rinsed in distilled water and left overnight in freshly prepared high iron diamine solution $(50 \mathrm{ml}$ distilled water with $120 \mathrm{mg}$ $N$ - $N^{\prime}$-dimethyl-m-phenylene diamine, $20 \mathrm{mg} N$ - $N^{\prime}$-dimethyl$p$-phenylene diamine and $1.4 \mathrm{ml} 60 \%$ ferric chloride).

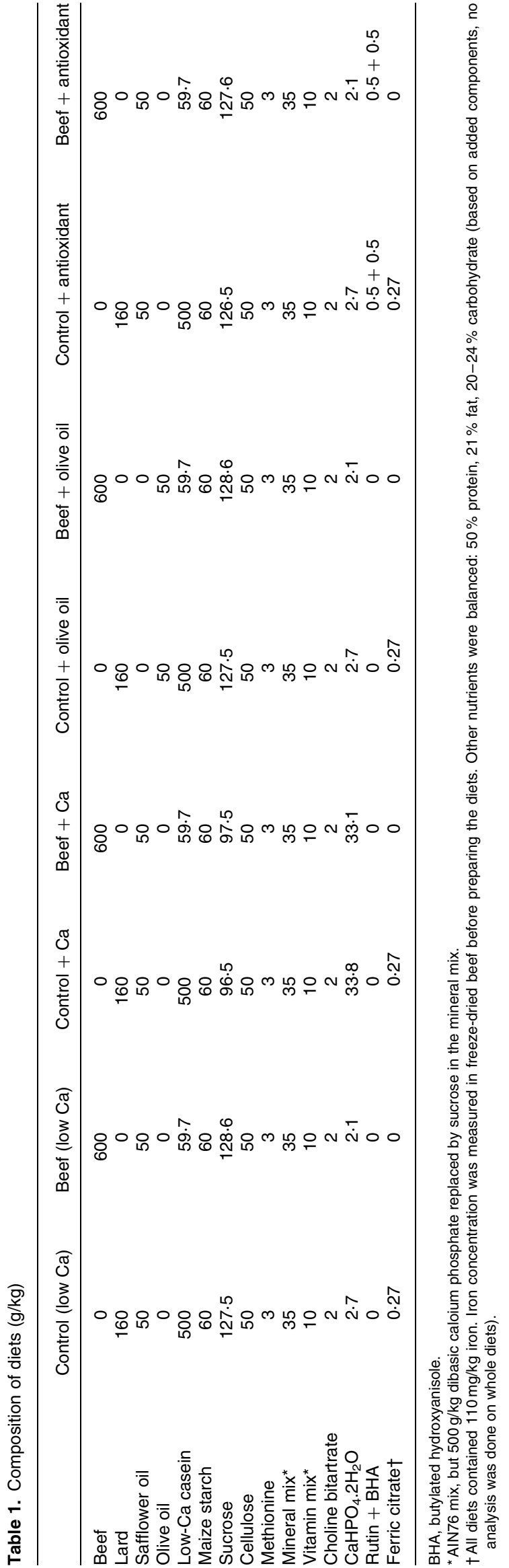


After rinsing, colons were counterstained in $1 \%$ Alcian blue solution for $30 \mathrm{~min}$. MDF number, and number of crypts per MDF, were scored blindly under light microscope at $\times 40$ magnification by a single reader.

\section{Preparation of faecal water}

Faecal pellets were collected under each cage of two rats for $24 \mathrm{~h}$, thus leading to five samples per group. Freeze-dried faeces were used to calculate dry faecal mass and to prepare faecal water by adding $1 \mathrm{ml}$ sterilized water to $0.3 \mathrm{~g}$ faeces. Samples were then incubated at $37^{\circ} \mathrm{C}$ for $1 \mathrm{~h}$, stirring thoroughly every $20 \mathrm{~min}$, followed by centrifugation at $20000 \mathrm{~g}$ for $10 \mathrm{~min}$. The aqueous phase was re-centrifuged at the same speed and duration and the subsequent supernatant (faecal water) collected and conserved at $-20^{\circ} \mathrm{C}$ until use.

\section{Thiobarbituric acid reactive substances and haem assay}

Thiobarbituric acid reactive substances (TBARS) were measured in faecal water according to Ohkawa et al. ${ }^{(15)}$, exactly as previously described ${ }^{(7)}$. Haem contents of freeze-dried faeces and of faecal water were measured by fluorescence according to Van den Berg et al. ${ }^{(16)}$ and Sesink et al. ${ }^{(5)}$, respectively, as already described ${ }^{7}$.

\section{Cytotoxicity assay of faecal water}

Cytotoxicity of faecal water was quantified on a cell line according to Bonneson et al. ${ }^{(17)}$, and as previously described ${ }^{(7)}$. Briefly, a cancerous mouse colonic epithelial cell line, CMT93 (ECAC), was seeded in ninety-six-well microtitre plates $\left(1.6 \times 10^{4}\right.$ cells/well in $200 \mu \mathrm{l}$ medium) and treated for $24 \mathrm{~h}$ with faecal water sample diluted at $10 \%(\mathrm{v} / \mathrm{v})$ in the culture medium. Cytotoxicity of each faecal water was quantified by the 3-(4,5-dimethyldiazol-2-yl)-2,5-diphenyl tetrazolium bromide test.

\section{Urinary 1,4-dihydroxynonane mercapturic acid assay}

Each rat was placed alone in a metabolic cage for $2 \mathrm{~d}$ during the fifth week of the experimental diet. The $24 \mathrm{~h}$ urine was collected under each cage of one rat, thus leading to ten samples per group. DHN-MA assay was done by competitive enzyme immunoassay as previously described ${ }^{(18)}$, using DHN-MAlinked acetylcholinesterase enzyme. Each urine sample was assayed in duplicate.

\section{Statistical analysis}

Results were analysed using Systat 10 software for Windows, and reported as means and standard deviations. Values were considered firstly using one-way ANOVA. If a significant difference was found between groups $(P<0.05)$ then each experimental group was compared to the control group using the Fisher's least significant difference test (ACF and MDF data), and the Dunnett multiple comparison test (all other data).

\section{Results}

Weight and food intake

Final body weight of rats was 198 (SD 3) g, without significant differences between groups at the end of the experimentation. Food intake was the same in all groups of rats (data not shown).

\section{Aberrant crypt foci and mucin-depleted foci data}

Beef meat diet doubled the number of MDF per colon compared to control rats, and increased the number of ACF per colon (both $P<0.01$; Fig. 1). The number of crypts per lesion also was enhanced by beef meat diet (Table 2).

Ca fully suppressed beef meat-induced promotion of ACF and MDF (Fig. 1), but did not reduce the mean number of crypts per lesion (Table 2). Antioxidant mix and olive oil significantly reduced meat-induced promotion of MDF number, but did not normalize it to control values (Table 2). In contrast, antioxidant mix and olive oil did not interfere significantly with beef meat-induced promotion of ACF number (Table 2). Thus, only Ca supplementation fully suppressed the beef-induced promotion of ACF and MDF.

Supplementation of no-meat control diet with antioxidant mix or olive oil did not modify ACF or MDF incidence (Table 2 ), as previously observed ${ }^{6}$. In contrast, surprisingly, high-Ca control diet-fed rats had more MDF and ACF in the colon than low-Ca control diet-fed rats, with more crypts per lesion $(P<0 \cdot 01$; Table 2$)$.

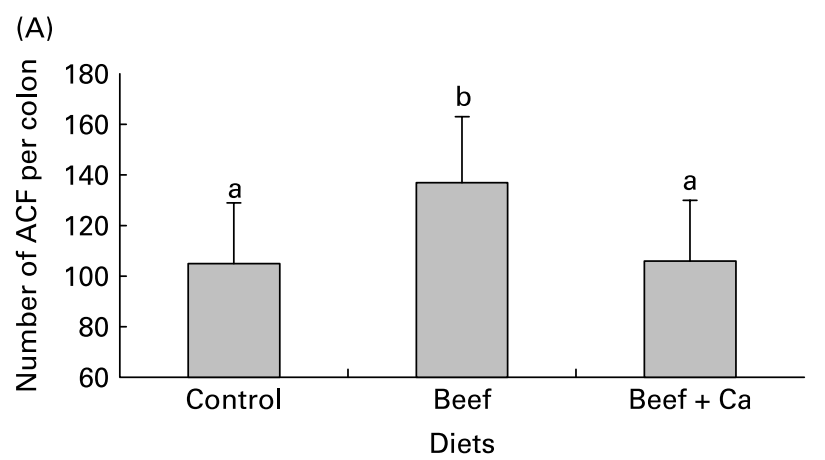

(B)

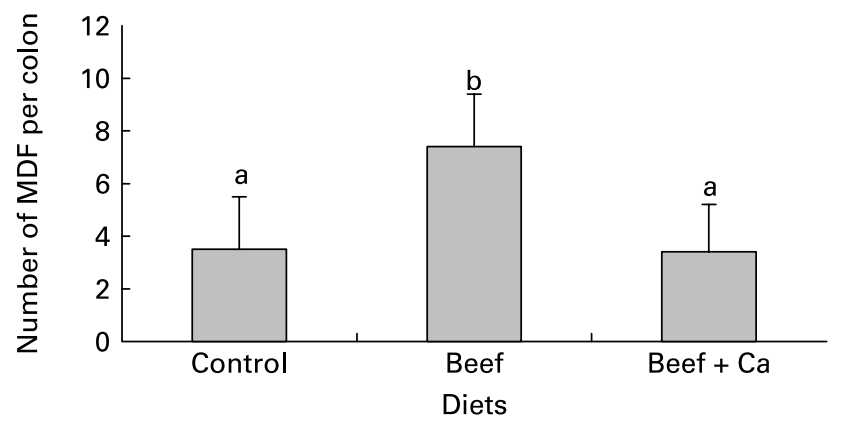

Fig. 1. Effect of beef meat and high-Ca beef meat diets on putative precancerous lesions per rat colon $107 \mathrm{~d}$ after the injection of dimethylhydrazine. (A), Number of aberrant crypt foci (ACF). (B), Number of mucin-depleted foci (MDF). Values are means with their standard deviations depicted by vertical bars $(n 10)$. ${ }^{a, b}$ Mean values with unlike letters were significantly different $(P<0.05)$. 
Table 2. Effect of meat-based diets on aberrant crypt foci (ACF) and mucin-depleted foci (MDF) in the colon of rats $107 \mathrm{~d}$ after the injection of dimethylhydrazine*

(Mean values and standard deviations)

\begin{tabular}{|c|c|c|c|c|c|c|c|c|c|c|c|c|c|}
\hline \multirow[b]{3}{*}{ Diets } & \multirow[b]{3}{*}{ Haem ( $\mu \mathrm{mol} / \mathrm{g}$ diet $)$} & \multicolumn{6}{|c|}{$\mathrm{ACF}$} & \multicolumn{6}{|c|}{ MDF } \\
\hline & & \multicolumn{2}{|c|}{ ACF/colon } & \multicolumn{2}{|c|}{ AC/colon } & \multicolumn{2}{|c|}{ Crypts/ACF } & \multicolumn{2}{|c|}{ MDF/colon } & \multicolumn{2}{|c|}{ MDC/colon } & \multicolumn{2}{|c|}{ Crypts/MDF } \\
\hline & & Mean & $\mathrm{SD}$ & Mean & $\mathrm{SD}$ & Mean & $\mathrm{SD}$ & Mean & $\overline{S D}$ & Mean & $\overline{S D}$ & Mean & $\mathrm{SD}$ \\
\hline Control & 0 & $105^{a}$ & 24 & $245^{a}$ & 52 & $2 \cdot 3^{a}$ & 0.2 & $3 \cdot 5^{\mathrm{a}}$ & $2 \cdot 0$ & $18 \cdot 2^{\mathrm{a}}$ & $15 \cdot 3$ & $4 \cdot 6^{a}$ & 1.7 \\
\hline Beef & 0.4 & $137^{\mathrm{b}}$ & 26 & $347^{\mathrm{b}}$ & 55 & $2 \cdot 6^{\mathrm{b}}$ & 0.2 & $7 \cdot 4^{\mathrm{b}}$ & $2 \cdot 0$ & $40 \cdot 7^{\mathrm{b}}$ & 18.9 & $5 \cdot 3^{a}$ & 1.6 \\
\hline Beef $+\mathrm{Ca}$ & 0.4 & $106^{a}$ & 24 & $265^{a}$ & 74 & $2 \cdot 5^{\mathrm{b}}$ & 0.2 & $3 \cdot 4^{\mathrm{a}}$ & 1.8 & $24 \cdot 3^{a}$ & $12 \cdot 6$ & $7 \cdot 8^{\mathrm{b}}$ & $3 \cdot 1$ \\
\hline Beef + antioxidant & 0.4 & $125^{\mathrm{b}}$ & 20 & $299^{c}$ & 60 & $2 \cdot 4^{\mathrm{a}}$ & 0.2 & $5 \cdot 3^{c}$ & 1.2 & $22 \cdot 5^{\mathrm{a}}$ & 5.3 & $4 \cdot 3^{\mathrm{a}}$ & 0.7 \\
\hline Beef + olive oil & 0.4 & $127^{\mathrm{b}}$ & 22 & $300^{c}$ & 40 & $2 \cdot 4^{\mathrm{a}}$ & 0.3 & $5 \cdot 6^{c}$ & $1 \cdot 1$ & $22 \cdot 4^{\mathrm{a}}$ & 9.5 & $3.9^{\mathrm{a}}$ & 1.4 \\
\hline Control + $\mathrm{Ca}$ & 0 & $130^{\mathrm{b}}$ & 22 & $365^{\mathrm{b}}$ & 71 & $2 \cdot 8^{\mathrm{C}}$ & 0.2 & $7 \cdot 6^{\mathrm{b}}$ & 3.0 & $58 \cdot 2^{\mathrm{c}}$ & 27.5 & $7 \cdot 6^{b}$ & 2.4 \\
\hline Control + antioxidant & 0 & $104^{\mathrm{a}}$ & 25 & $258^{a}$ & 71 & $2 \cdot 5^{\mathrm{b}}$ & 0.2 & $3 \cdot 8^{a}$ & 2.5 & $15 \cdot 6^{a}$ & 13.0 & $4 \cdot 0^{\mathrm{a}}$ & $1 \cdot 2$ \\
\hline Control + olive oil & 0 & $107^{a}$ & 22 & $243^{a}$ & 48 & $2 \cdot 3^{a}$ & 0.2 & $3 \cdot 2^{\mathrm{a}}$ & 1.3 & $14 \cdot 7^{\mathrm{a}}$ & $8 \cdot 8$ & $4 \cdot 4^{\mathrm{a}}$ & 1.4 \\
\hline
\end{tabular}

AC, aberrant crypts; MDC, Mucin-depleted crypts.

a,b,c Mean values within a column with unlike superscript letters were significantly different $(P<0.05)$

*Ten rats per dietary group. Diets were based on a low-Ca formula, and were balanced for Fe $(110 \mathrm{mg} / \mathrm{kg})$. See Table 1 for precise compositions.

Faecal haem, thiobarbituric acid reactive substances and cytotoxicity

Haem intake and faecal haem values matched the study design: as expected, little haem was detected in faeces of control rats, in contrast with beef meat-fed rats (Table 3 ). We also measured haem concentrations in faecal water because, according to bile acid studies, the soluble fraction of colonic contents would interact more strongly with the mucosa than the insoluble fraction. As expected, haem concentration in faecal water depended directly on haem level in beef-based diets (Table 3). However, rats fed the beef meat high-Ca diet had little haem in faecal water, as previously observed ${ }^{(6)}$.

Haem can induce the formation of peroxyl radicals in fats, which may be cytotoxic and cleave DNA in vivo. Lipid peroxidation was thus measured in faecal water by the TBARS assay. Lipid peroxidation correlated with haem concentration in faecal water (Table 3); $r 0.95, P=0.0002$ ). Ca almost normalized beefinduced lipid peroxidation to control level (66 and $33 \mu \mathrm{M}$-malondialdehyde equivalent, respectively), but antioxidant mix or olive oil did not reduce peroxide values (130 and $148 \mu \mathrm{M}-\mathrm{mal}-$ ondialdehyde equivalent, similar to $141 \mu \mathrm{M}$ in beef meat-fed rats). Furthermore, as already seen, faecal water of beef meatfed rats was cytotoxic to CMT93 cells. Ca fully inhibited beef meat-induced cytotoxicity of faecal water, but antioxidant mix and olive oil did not.

\section{Urinary 1,4-dihydroxynonane mercapturic acid excretion}

Table 3 shows that beef meat-based diet increased urinary DHN-MA excretion 15-fold compared with control diet $(P<0.001)$. Ca and olive oil did not reduce DHN-MA excretion in beef meat-fed rats, while antioxidant mix gave a slight decrease, though statistically significant.

\section{Discussion}

The present data confirm that a red meat diet promotes colon carcinogenesis in rats. The results also establish that red meat

Table 3. Effect of meat-based diets on faecal values in rats, notably haem, lipoperoxides and cytotoxicity of faecal water ${ }^{*}$ (Mean values and standard deviations)

\begin{tabular}{|c|c|c|c|c|c|c|c|c|c|c|c|c|c|c|}
\hline \multirow[b]{2}{*}{ Diets } & \multicolumn{2}{|c|}{$\begin{array}{l}\text { Haem intake } \\
\qquad(\mu \mathrm{mol} / \mathrm{d})\end{array}$} & \multicolumn{2}{|c|}{$\begin{array}{l}\text { Dry faecal } \\
\text { mass }(g / d)\end{array}$} & \multicolumn{2}{|c|}{$\begin{array}{l}\text { Haem in } \\
\text { faeces } \\
(\mu \mathrm{mol} / \mathrm{g})\end{array}$} & \multicolumn{2}{|c|}{$\begin{array}{c}\text { Haem in } \\
\text { faecal water } \\
(\mu \mathrm{M})\end{array}$} & \multicolumn{2}{|c|}{$\begin{array}{c}\text { TBARS in fae- } \\
\text { cal water MDA } \\
\text { equivalents } \\
(\mu \mathrm{M})\end{array}$} & \multicolumn{2}{|c|}{$\begin{array}{l}\text { Cytotoxicity } \\
\text { on CMT93 } \\
\text { cells (\% cells } \\
\text { lysed) }\end{array}$} & \multicolumn{2}{|c|}{$\begin{array}{c}\text { Urinary DHN-MA } \\
\text { (ng/d) }\end{array}$} \\
\hline & Mean & $\mathrm{SD}$ & Mean & SD & Mean & SD & Mean & $\mathrm{SD}$ & Mean & SD & Mean & SD & Mean & SD \\
\hline Control & $0^{a}$ & & $0.49^{a}$ & 0.12 & $0.56^{a}$ & 0.65 & $7^{\mathrm{a}}$ & 6 & $33^{a}$ & 9 & $35^{\mathrm{a}}$ & 8 & $58 \cdot 2^{a}$ & $7 \cdot 5$ \\
\hline Beef & $3 \cdot 8^{\mathrm{b}}$ & 0.3 & $0.68^{b}$ & 0.05 & $2.94^{\mathrm{b}}$ & 1.01 & $49^{b}$ & 7 & $141^{\mathrm{b}, \mathrm{c}, \mathrm{d}}$ & 16 & $63^{b}$ & 12 & $899 \cdot 4^{\mathrm{b}}$ & 244.7 \\
\hline Beef $+\mathrm{Ca}$ & $3.8^{\mathrm{b}}$ & 0.3 & $0.99^{c}$ & 0.14 & $2 \cdot 63^{b}$ & $1 \cdot 28$ & $9^{a}$ & 4 & $66^{\mathrm{e}}$ & 7 & $26^{\mathrm{a}, \mathrm{c}}$ & 15 & $858 \cdot 3^{b}$ & $262 \cdot 3$ \\
\hline Beef + antioxidant & $3 \cdot 6^{\mathrm{b}}$ & 0.2 & $0.56^{\mathrm{a}}$ & 0.07 & $3 \cdot 20^{\mathrm{b}}$ & 1.80 & $67^{\mathrm{b}}$ & 17 & $130^{d}$ & 35 & $65^{\mathrm{b}}$ & 10 & $630 \cdot 5^{c}$ & $169 \cdot 8$ \\
\hline Beef + olive oil & $3 \cdot 6^{\mathrm{b}}$ & 0.3 & $0.55^{a}$ & 0.11 & $3 \cdot 11^{\mathrm{b}}$ & 0.70 & $64^{b}$ & 21 & $148^{c}$ & 16 & $66^{b}$ & 9 & $747 \cdot 1^{\mathrm{b}, \mathrm{c}}$ & $232 \cdot 8$ \\
\hline Control + Ca & $0^{\mathrm{a}}$ & & $0.79^{\mathrm{b}}$ & $0 \cdot 10$ & $0.53^{a}$ & 0.51 & $6^{a}$ & 1 & $22^{a}$ & 8 & $16^{c}$ & 6 & $36 \cdot 4^{a}$ & 6.5 \\
\hline Control + antioxidant & $0^{\mathrm{a}}$ & & $0.58^{a}$ & 0.06 & $0.39^{a}$ & 0.35 & $9^{a}$ & 4 & $43^{a}$ & 21 & $32^{\mathrm{a}}$ & 19 & $40 \cdot 6^{a}$ & $2 \cdot 4$ \\
\hline Control + olive oil & $0^{a}$ & & $0.56^{\mathrm{a}}$ & 0.07 & $0.52^{\mathrm{a}}$ & 0.43 & $7^{\mathrm{a}}$ & 5 & $39^{a}$ & 14 & $50^{\mathrm{b}}$ & 12 & $55 \cdot 6^{a}$ & $23 \cdot 4$ \\
\hline
\end{tabular}

DHN-MA, 1,4-dihydroxynonane mercapturic acid; MDA, malondialdehyde; TBARS, thiobarbituric acid reactive substances.

a-d Mean values within a column with unlike superscript letters were significantly different $(P<0.05)$.

${ }^{*}$ Faecal values, five cages per group; urine values, ten rats per group. Diets were based on a low-Ca formula, and were balanced for Fe (110 mg/kg). See Table 1 for precise compositions. 
promotion can be suppressed by dietary $\mathrm{Ca}$. In addition, faecal water cytotoxicity and lipoperoxide level were linked with haem-induced promotion.

Red meat promoted ACF and MDF in the colon of carcinogen-induced rats, and meat promotion was associated with faecal water haem, cytotoxicity and TBARS, in line with our previous study ${ }^{(7)}$. The mechanism of haem promotion is not known, and may be linked to the stimulation of the endogenous production of N-nitroso compounds ${ }^{(19,20)}$. Alternatively, we suggest promotion is linked to peroxidation and cytotoxicity. We have explored the effect of faecal water from beef-fed rats on normal $(\mathrm{Apc}+/+)$ and premalignant colonic cells (Apc Min/+). Results show that Apc mutated cells survive haem-induced faecal lipoperoxides, notably 4-hydroxynonenal (HNE) that is toxic to normal cells. Selection of mutated cells by cytotoxic lipoperoxides may explain haem promotion of colon carcinogenesis ${ }^{(21)}$. Beef diet reduces caspase- 3 activity in the rat colonic mucosa, thus decreasing apoptosis induction ${ }^{(22)}$. In addition, loss of adenomatous Polyposis coli protein induces histone deacetylase 2: it is overexpressed in polyps of adenomatous Polyposis coli proteindeficient mice, and it prevents apoptosis of colonic cells $^{(23,24)}$. Furthermore, HNE alters histone acetylation ${ }^{(25)}$. Therefore, the modification of histone acetylation by meatinduced HNE may reduce apoptosis induction and explain the selection of Apc-mutated cells. This speculation on the meat-promotion mechanism is supported by the present study: ACF and MDF promotion in beef meat-fed rats was associated with high faecal lipoperoxides and cytotoxicity, and, as discussed later, dietary changes that normalized faecal lipoperoxides and cytotoxicity also suppressed beef meat- promotion.

$\mathrm{Ca}$ added on top of the beef meat diet normalized the number of ACF and MDF at the same low level as the control group, a protection already observed against haemin-induced promotion $^{(6)}$. In faeces from rats given high-Ca beef meat diet, haem concentration was high (similar to beef meat-fed rats), but faecal water haem level was low (similar to no-meat control rats) (Table 3). Calcium phosphate precipitates haem in the gut, and little haem remains available to induce lipoperoxidation, as previously showed with haemin ${ }^{(6,9)}$. Faecal water thus contained little lipid peroxide and showed little cytotoxic activity (Table 3 ). The trapping of haem by $\mathrm{Ca}$ abolished carcinogenesis promotion. This confirms that haem is the cause of red meat promotion. The results also suggest that $\mathrm{Ca}$ can reduce colorectal cancer risk in meat-eaters. It might explain discrepancies between clinical trials with $\mathrm{Ca}$ supplements, since results were not analysed based on meat consumption by volunteers. This could be looked for in a prospective cohort study, to find out whether the protective effect of $\mathrm{Ca}$ against red meat promotion can also be seen in man. Similarly, an epidemiological study shows that chlorophyll from vegetables attenuates the elevated risk of colon cancer associated with red meat intake ${ }^{(26)}$.

No protection against beef meat promotion was afforded by the antioxidant mix or by olive oil (Table 2). These supplements did not normalize faecal values of haem lipoperoxides and cytotoxicity either (Table 3 ). The present results conflict with a previous study in which the antioxidant mix or olive oil had been effective against haemin-induced promotion $^{(6)}$. This conflict suggests that dietary haemin is not a suitable model for red meat to test preventive strategies in rodents. We speculate that antioxidant molecules added to the diet can directly prevent the effect of haemin powder on dietary oil ${ }^{(6)}$. Here, in contrast, protein-bound haem in red meat might have been protected from the antioxidant effect. Furthermore, since faecal water lipoperoxides and cytotoxicity are associated with haem-induced carcinogenesis, here and in previous studies ${ }^{(6,7)}$, we suggest they can be used as short-term biomarkers to screen preventive strategies against red meatinduced promotion of colon cancer.

An unexpected result of the present study was that rats eating a high-Ca control diet had more ACF and more MDF than low-Ca control diet-fed control rats. This promotion by calcium phosphate in a high-fat context was not seen in a low-fat context, in our previous haemin study ${ }^{(6)}$. It is generally agreed that $\mathrm{Ca}$ reduces the risk of colorectal cancer ${ }^{(27)}$, and a meta-analysis study shows that Ca modestly decreases tumour incidence in rats ${ }^{(28)}$. However, in fourteen studies out of thirty-two, a non-significant tumour incidence increase was seen in Ca-fed rats. The meta-analysis also shows that some $\mathrm{Ca}$ salts are more protective than others, and that calcium phosphate affords no protection ${ }^{(28)}$. Calcium phosphate (which we used here) sometimes promotes ACF or tumours ${ }^{(29,30)}$. For instance, Bull et al. ${ }^{(30)}$ showed that calcium phosphate promotes colon tumourigenesis in two genetic contexts (Sprague-Dawley and Fischer 344 rats). In both types of rat the promotion was more important in $30 \%$ fat diet-fed rats than in $3 \%$ fat diet-fed rats ${ }^{(30)}$. Phosphate, not $\mathrm{Ca}$, might be the promoting nutrient, an issue discussed by Bruce et al. ${ }^{(31)}$. To conclude, promotion by calcium phosphate in a high-fat context was unexpected, but has already been reported.

Another surprise here is that all beef meat diets increased urinary DHN-MA excretion more than 10 -fold. We have recently proposed urinary DHN-MA as a non-invasive biomarker of haem Fe-induced promotion of carcinogenesis. Indeed, DHN-MA excretion increases dramatically in rats given high-haem diets, and the excretion parallels ACF and MDF numbers in azoxymethane-initiated rats ${ }^{(8)}$. However, in the present study, the addition of $\mathrm{Ca}$ to the meat diet did not reduce DHN-MA excretion while it normalized ACF and MDF promotion. DHN-MA is the major urinary metabolite of HNE, a lipid peroxidation product. DHN-MA excretion reflects endogenous HNE formation in the body, together with formation in the diet ${ }^{(8)}$, the latter being probably quantitatively the most important ${ }^{(32)}$, while preneoplastic lesions such as ACF and MDF may be due to lipid peroxidation occurring locally in the colon lumen. One can hypothesize that Ca blocks haem in the intestine ${ }^{(9)}$ but not in the diet, because of its powdered form, so the overall DHN-MA excretion is not significantly reduced by the addition of $\mathrm{Ca}$ although HNE formation is reduced in the colon lumen. Indeed, in a previous work, we have shown that HNE was found three times less in the faeces of rats fed beef + calcium diet as compared to beef $\operatorname{diet}^{(21)}$. It thus seems that DHN-MA is a biomarker of exposure to a promoting dose of haem in the diet, but DHN-MA is not a risk factor. However, measurement of HNE in faeces, which can reflect HNE in colon lumen, could be an indicator of the colon cancer risk associated with diets.

In conclusion, the present study shows for the first time $\mathrm{Ca}$ prevention of red meat promotion of colon carcinogenesis. 
The present study supports the concept that toxicity associated with the excess of a useful nutrient like haeminic Fe may be prevented by another nutrient like $\mathrm{Ca}$. Yoghurt or cheese can be eaten after red meat, provided portions are small enough to avoid fat overload. We found hardly any examples of a similar antidote effect, except maybe the lactulose prevention of protein-induced hepatic encephalopathy ${ }^{(33)}$. This Ca preventive effect should be looked for in a cohort study by crossing haem and $\mathrm{Ca}$ intake with adenoma or cancer risk. Furthermore, different haem forms do not have the same promoting potency and cannot be antagonized by identical agents, since the haemin effect is not identical to the red meat effect. Lastly, faecal water lipoperoxidation and cytotoxicity may be responsible, at least in part, for haem-induced promotion of colon carcinogenesis.

\section{Acknowledgements}

This study was supported in part by the INRA, the DGER and the French region Midi-Pyrénées. We thank Xavier Blanc (UPAE) for the preparation of experimental diets, MarieClaude Nicot for the assay of $\mathrm{Ca}$ and $\mathrm{Fe}$ in meats, and Raymond Gazel and Florence Blas Y Estrada for the care of the animals.

\section{References}

1. Larsson SC \& Wolk A (2006) Meat consumption and risk of colorectal cancer: a meta-analysis of prospective studies. Int $J$ Cancer 119, 2657-2664.

2. Norat T, Lukanova A, Ferrari P \& Riboli E (2002) Meat consumption and colorectal cancer risk: dose-response meta-analysis of epidemiological studies. Int J Cancer 98, 241-256.

3. Lee DH, Anderson KE, Harnack LJ, Folsom AR \& Jacobs DR Jr (2004) Heme iron, zinc, alcohol consumption, and colon cancer: Iowa Women's Health Study. J Natl Cancer Inst 96, 403-407.

4. Larsson SC, Rafter J, Holmberg L, Bergkvist L \& Wolk A (2005) Red meat consumption and risk of cancers of the proximal colon, distal colon and rectum: the Swedish Mammography Cohort. Int J Cancer 113, 829-834.

5. Sesink ALA, Termont DSML, Kleibeuker JH \& Vandermeer R (1999) Red meat and colon cancer: the cytotoxic and hyperproliferative effects of dietary heme. Cancer Res 59, 5704-5709.

6. Pierre F, Tache S, Petit CR, Van der Meer R \& Corpet DE (2003) Meat and cancer: haemoglobin and haemin in a low-calcium diet promote colorectal carcinogenesis at the aberrant crypt stage in rats. Carcinogenesis 24, 1683-1690.

7. Pierre F, Freeman A, Tache S, Van der Meer R \& Corpet DE (2004) Beef meat and blood sausage promote the formation of azoxymethane-induced mucin-depleted foci and aberrant crypt foci in rat colons. $J$ Nutr 134, 2711-2716.

8. Pierre F, Peiro G, Tache S, Cross AJ, Bingham SA, Gasc N, Gottardi G, Corpet DE \& Gueraud F (2006) New marker of colon cancer risk associated with heme intake: 1,4-dihydroxynonane mercapturic acid. Cancer Epidemiol Biomarkers Prev 15, 2274-2279.

9. Sesink ALA, Termont DSML, Kleibeuker JH \& VanDerMeer R (2001) Red meat and colon cancer: dietary haem-induced colonic cytotoxicity and epithelial hyperproliferation are inhibited by calcium. Carcinogenesis 22, 1653-1659.
10. Karkare MR, Clark TD \& Glauert HP (1991) Effect of dietary calcium on colon carcinogenesis induced by a single injection of 1,2-dimethylhydrazine in rats. J Nutr 121, 568-577.

11. American Institute of Nutrition (1977) Report of the American Institute of Nutrition Ad Hoc Committee on standards for nutritional studies. J Nutr 107, 1340-1348.

12. Bird RP (1987) Observation and quantification of aberrant crypts in murine colon treated with a colon carcinogen: preliminary findings. Cancer Lett 37, 147-151.

13. Femia AP, Dolara P, Giannini A, Salvadori M, Biggeri A \& Caderni G (2007) Frequent mutation of Apc gene in rat colon tumors and mucin-depleted foci, preneoplastic lesions in experimental colon carcinogenesis. Cancer Res 67, 445-449.

14. Caderni G, Femia AP, Giannini A, Favuzza A, Luceri C, Salvadori M \& Dolara P (2003) Identification of mucin-depleted foci in the unsectioned colon of azoxymethane-treated rats: correlation with carcinogenesis. Cancer Res 63, 2388-2392.

15. Ohkawa H, Ohishi N \& Yagi K (1979) Assay for lipid peroxides in animal tissues by thiobarbituric acid reaction. Anal Biochem 95, 351-358.

16. Van den Berg JW, Koole-Lesuis R, Edixhoven-Bosdijk A \& Brouwers N (1988) Automating the quantification of heme in feces. Clin Chem 34, 2125-2126.

17. Bonneson C, Eggleston IM \& Hayes JD (2001) Dietary indoles and isothiocyanates that are generated from cruciferous vegetables can both stimulate apoptosis and confer protection against DNA damage in human colon cell lines. Cancer Res 61, 6120-6130.

18. Gueraud F, Peiro G, Bernard H, et al. (2006) Enzyme immunoassay for a urinary metabolite of 4-hydroxynonenal as a marker of lipid peroxidation. Free Radic Biol Med 40, 54-62.

19. Bingham SA, Pignatelli B, Pollock JRA, Ellul A, Malaveille C, Gross G, Runswick S, Cummings JH \& Oneill IK (1996) Does increased endogenous formation of $\mathrm{N}$-nitroso compounds in the human colon explain the association between red meat and colon cancer? Carcinogenesis 17, 515-523.

20. Lunn JC, Kuhnle G, Mai V, Frankenfeld C, Shuker DE, Glen RC, Goodman JM, Pollock JR \& Bingham SA (2006) The effect of haem in red and processed meat on the endogenous formation of $\mathrm{N}$-nitroso compounds in the upper gastrointestinal tract. Carcinogenesis 28, 685-690.

21. Pierre F, Tache S, Gueraud F, Rerole AL, Jourdan ML \& Petit C (2007) Apc mutation induces resistance of colonic cells to lipoperoxide-triggered apoptosis induced by faecal water from haem-fed rats. Carcinogenesis 28, 321-327.

22. Yang LP, Mutanen M, Cheng YJ \& Duan RD (2002) Effects of red meat and fiber in high fat diet on activities of sphingomyelinase, ceramidase and caspase- 3 in rat colonic mucosa. $J$ Nutr Biochem 13, 499-504.

23. Huang X \& Guo B (2006) Adenomatous polyposis coli determines sensitivity to histone deacetylase inhibitor-induced apoptosis in colon cancer cells. Cancer Res 66, 9245-9251.

24. Zhu P, Martin E, Mengwasser J, Schlag P, Janssen KP \& Gottlicher M (2004) Induction of HDAC2 expression upon loss of APC in colorectal tumorigenesis. Cancer Cell 5, 455-463.

25. Rahman I, Marwick J \& Kirkham P (2004) Redox modulation of chromatin remodeling: impact on histone acetylation and deacetylation, NF-kappaB and pro-inflammatory gene expression. Biochem Pharmacol 68, 1255-1267.

26. Balder HF, Vogel J, Jansen MC, Weijenberg MP, van den Brandt PA, Westenbrink S, van der Meer R \& Goldbohm RA (2006) Heme and chlorophyll intake and risk of colorectal cancer in the Netherlands cohort study. Cancer Epidemiol Biomarkers Prev 15, 717-725.

27. Newmark HL \& Lipkin M (1992) Calcium, vitamin-D, and colon cancer. Cancer Res 52, S2067-S2070.

28. Corpet DE \& Pierre F (2005) How good are rodent models of carcinogenesis in predicting efficacy in humans? A systematic 
review and meta-analysis of colon chemoprevention in rats, mice and men. Eur J Cancer 41, 1911-1922.

29. Weisburger JH, Braley J, Reinhardt J, Aliaga C, Rivenson A, Hard GC, Zhang XM, Takahashi M, Esumi H \& Sugimura T (1994) The role of fat and calcium in the production of foci of aberrant crypts in the colon of rats fed 2-amino-1-methyl-6-phenylimidazo[4,5b]pyridine. Environ Health Perspect 102, 53-55.

30. Bull A, Bird RP, Bruce WR, Nigro N \& Medline A (1987) Effect of calcium on azoxymethane induced intestinal tumors in rats. Gastroenterology 92, 1332.
31. Bruce WR, Giacca A \& Medline A (2001) Possible mechanisms relating diet to colorectal cancer risk. In European Conference on Nutrition and Cancer, pp. 1-7, 21-24 June. Lyon, France: IARC Scientific Publications.

32. Gasc N, Tache S, Rathahao E, Bertrand-Michel J, Roques V \& Gueraud F (2007) 4-Hydroxynonenal in foodstuffs: heme concentration, fatty acid composition and freeze-drying are determining factors. Redox Rep 12, 40-44.

33. Blei AT \& Cordoba J (2001) Hepatic encephalopathy. Am J Gastroenterol 96, 1968-1976. 